\title{
Aquatic Ecotoxicity of Microplastics and Nanoplastics: Lessons Learned from Engineered Nanomaterials
}

\author{
Sinja Rist and Nanna Bloch Hartmann
}

\begin{abstract}
The widespread occurrence of microplastics in the aquatic environment is well documented through international surveys and scientific studies. Further degradation and fragmentation, resulting in the formation of nanosized plastic particles - nanoplastics - has been highlighted as a potentially important issue. In the environment, both microplastics and nanoplastics may have direct ecotoxicological effects, as well as vector effects through the adsorption of co-contaminants. Plastic additives and monomers may also be released from the polymer matrix and cause adverse effects on aquatic organisms. Although limited information regarding the ecotoxicological effects of nano- and microplastics is available at present, their small size gives rise to concern with respect to the adverse effects and dislocation of these particles inside organisms - similar to issues often discussed for engineered nanomaterials. In the same way, transport of co-contaminants and leaching of soluble substances are much debated issues with respect to the ecotoxicology of nanomaterials.

In this chapter, we draw on existing knowledge from the field of ecotoxicology of engineered nanomaterials to discuss potential ecotoxicological effects of nanoand microplastics. We discuss the similarities and differences between nano- and microplastics and engineered nanomaterials with regard to both potential effects and expected behaviour in aquatic media. One of the key challenges in ecotoxicology of nanomaterials has been the applicability of current test methods, originally intended for soluble chemicals, to the testing of particle suspensions. This often requires test modifications and special attention to physical chemical characterisation and data interpretation. We present an overview of lessons learned from
\end{abstract}

This chapter has been externally peer-reviewed.

S. Rist $(\bowtie)$ and N.B. Hartmann

Department of Environmental Engineering, Technical University of Denmark, 2800 Kongens

Lyngby, Denmark

e-mail: siri@env.dtu.dk 
nanomaterials and offer suggestions on how these can be transferred to recommendations for ecotoxicity testing of nano- and microplastics.

Keywords Biological effects, Nanoparticles, Nanotoxicology, Test methods, Vector effects

\section{Engineered Nanomaterials Versus Plastic Particles: Comparing Apples and Oranges?}

Over the last half century, it has become increasingly clear that environmental pollution presents a global societal challenge due to immediate and long-term hazards posed by chemicals in the environment. The focus of researchers, legislators and the population has been on chemicals such as pesticides, persistent organic pollutants, heavy metals, pharmaceuticals and endocrine-disrupting chemicals, as well as the effect of chemical mixtures. The common denominator for these groups of chemicals is that they are most often soluble in aqueous media. Ecotoxicology is a multidisciplinary field, integrating ecology and toxicology. It is the study of potentially harmful effects of chemicals on biological organisms, from the cellular to the ecosystem level. Standardised and harmonised ecotoxicological test methods have been developed within the frameworks of OECD and ISO to assess the environmental fate and effects of chemicals.

During the last decade, a new group of chemical substances has entered the limelight, namely, particles. The increasing use of nanotechnology and production of engineered nanomaterials has sharpened the public, scientific and regulatory focus on their potential consequences for the environment and human health, leading to the formation of the new scientific field of ecotoxicology of nanomaterials. The concerns apply not only to engineered nanomaterials but also to unintentionally produced anthropogenic nanomaterials such as ultrafine particles resulting from combustion processes. Similarly, it is becoming increasingly clear that microscopic plastic particles are widespread in the environment, resulting from industrial use, human activities and inadequate waste management. This plastic debris is found in the micrometre size range (i.e. microplastics) although submicron-sized plastic particles (i.e. nanoplastics) are also expected to be formed in the environment through continuous fragmentation of larger plastic particles $[1,2]$. Microplastics are commonly defined as plastic particles smaller than $5 \mathrm{~mm}$ [3], whereas no common definition for nanoplastics has yet been established. The term has been used for particles $<1 \mu \mathrm{m}$ as well as $<100 \mathrm{~nm}[2,4]$. Engineered nanomaterials, on the other hand, are more unambiguously defined as having at least one dimension in the size range of 1-100 $\mathrm{nm}$ [5]. Nanoparticles are a subgroup of nanomaterials possessing three dimensions within this size range. The term 'nanomaterials' is generally used here; however, 'nanoparticles' are referred to in certain places to emphasise the particulate nature of the material. To date, no established analytical methods exist for the detection of nanoplastics in the aquatic 
environment, and no studies have demonstrated their presence [2]. However, laboratory studies have shown the formation of nanoplastics down to sizes of $30 \mathrm{~nm}$ during artificial weathering of larger plastic materials, using nanoparticle tracking analysis [6]. This is a strong indication that this process can also take place in the environment. Particles as emerging environmental pollutants call for a better understanding of their environmental behaviour and potentially harmful effects on organisms. Ecotoxicity testing of particles represents a shift in test paradigm away from testing of soluble chemicals and demands reconsideration of existing test methods and procedures, including the standardised methods developed by OECD and ISO $[7,8]$. On the one hand, parallels can generally be drawn between ecotoxicological testing of particles, independent of whether those particles are engineered nanomaterials or plastic particles [9]. On the other hand, it is important to understand where the similarities end, in order to avoid redundant testing, use of inappropriate test methods and generation of meaningless data. Nano- and microplastics cover a wide range in terms of particle sizes. To illustrate this: If a $1 \mathrm{~mm}$ particle corresponded to the size of the Earth, then a nanosized particle would correspond to the International Space Station in the orbit around it, i.e. differing in size by six orders of magnitude. Resemblances, in terms of behaviour, fate and effects, are more likely to occur for particles that are similar in size. Therefore the similarities between engineered nanomaterials and nano- and microplastic particles are more likely to apply for smaller microplastics of up to a few microns as well as the submicron-sized nanoplastic particles, which will be the main focus of this chapter. Further noteworthy differences exist in terms of their chemical properties, sources and their related methodological challenges, as described in further detail below.

\section{Sources, Emissions and Regulation}

The potential sources and routes by which engineered nanomaterials and nano- and microplastics enter the environment are somewhat similar (see Fig. 1). As their name suggests, engineered nanomaterials are intentionally designed and produced for specific applications, processes or products. Production can take place by synthesis (bottom-up approach) or comminution of larger materials (top-down approach). This is comparable to the production of primary nano- and microplastics, for example, microbeads intentionally produced for cosmetic products or plastic pellets used as feeding material in plastic production. Depending on the definitions applied, primary nanoplastics would actually fall under the definition of engineered nanomaterials. An estimated amount of more than 4,000 t of primary microplastic beads were used in cosmetics in Europe in 2012 [10]. Nonetheless, primary microplastics only represent a small fraction of the estimated overall environmental microplastics load [11], a fraction, however, which can relatively easily be addressed and reduced. The main sources of nano- and microplastic pollution, however, are uncontrolled processes such as abrasion and degradation of larger plastic products and fragments, i.e. secondary sources of anthropogenic origin [12]. These sources include 


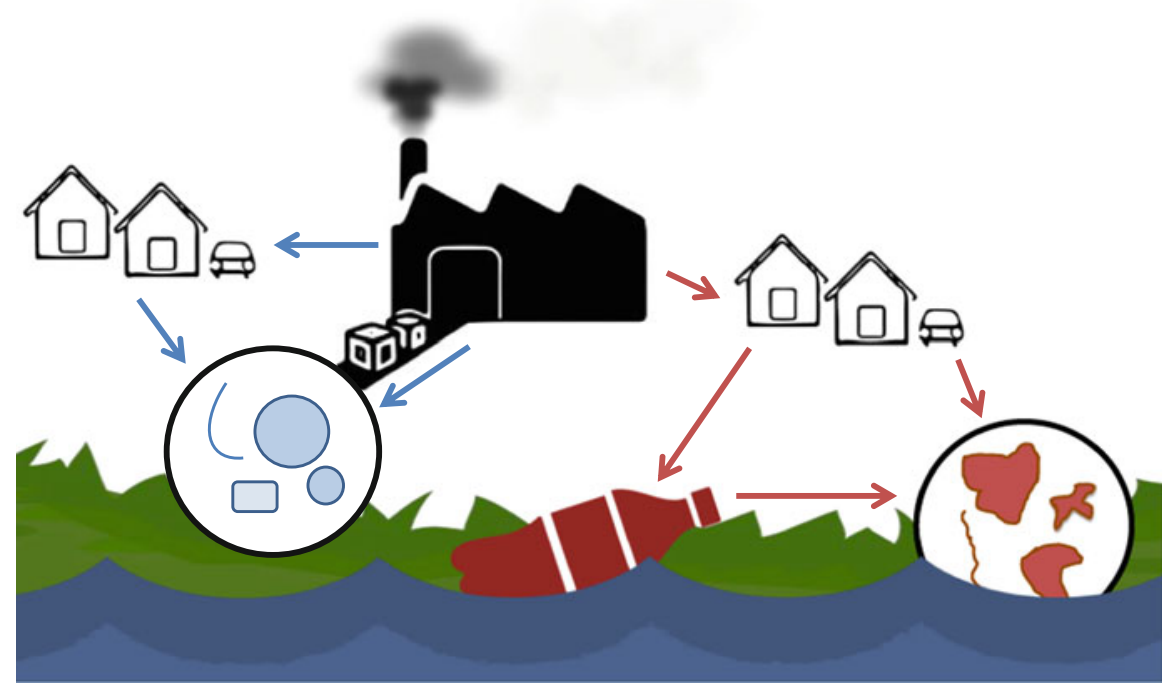

Fig. 1 Nano- and microplastics and engineered nanomaterials can enter the environment through different processes: intentional industrial manufacturing (as in the case of engineered nanomaterials and primary nano- and microplastics) or through uncontrolled anthropogenic processes (secondary nano- and microplastics). The different sources result in particles with different shapes, morphologies, compositions, sizes, etc. Particles manufactured under controlled industrial conditions tend to be more homogenous and uniform in their properties. Blue, primary sources; red, secondary sources

mismanaged plastic waste, either discarded in the environment directly or improperly collected and disposed of in landfills, subsequently reaching the environment by wind- or water-driven transport [13]. Also, industrial abrasion processes (e.g. air blasting), synthetic paints and car tyres are thought to contribute significantly to the generation of microplastics [11]. Wind and surface run-off water can transport these to aquatic ecosystems. Another important source is synthetic textiles, which have been shown to release large amounts of microplastic fibres into waste water during washing [14]. The relative importance of secondary sources is unique to micro- and nanoplastics, compared to engineered nanomaterials, in the sense that engineered nanomaterials are produced through controlled industrial processes and not generated from the bulk material in the environment. Their release is thereby linked to specific products or industrial applications and therefore comparable to primary microplastics.

The differences in sources between engineered/industrially produced primary particles and unintentionally produced secondary particles have consequences for risk management and regulatory options. For engineered nanomaterials, regulatory measures can ensure that risk is minimised to acceptable levels through upstream regulation of their specific production and use. Regulations addressing criteria for air emissions from various combustion processes can help to reduce the release of 
unintentionally produced anthropogenic nanomaterials. For micro- and nanoplastics, upstream regulation may be effective in reducing the environmental emissions of primary microplastics. Examples are the US 'Microbead-Free Waters Act of 2015' [15] prohibiting plastic microbeads in rinse-off cosmetics including toothpaste as well as the upcoming UK ban on microbeads in cosmetics by 2017 [16]. For secondary microplastics, on the other hand, reducing their environmental occurrence involves taking general action against plastics entering the environment during all steps of plastic production, use and waste management. Taxation of, or a ban on, single-use plastic shopping bags [17] and bottle return systems [18] are examples of regulatory measures aimed at reducing the general environmental plastic load. Once the plastic has entered the environment, the formation of microplastics is governed by the inherent properties of the plastic and the environmental conditions [19] and thereby practically impossible to mitigate through regulatory measures.

\section{Material Synthesis, Chemical Composition and Consequences for Environmental Detection}

A clear difference between engineered nanomaterials and nano- and microplastics relates to their chemical composition. In principle, engineered nanomaterials can be produced from any solid material. Higher production volume engineered nanomaterials are typically made from metals or metal oxides (such as $\mathrm{TiO}_{2}, \mathrm{CeO}_{2}$ and $\mathrm{Ag}$ ) or from carbon (such as carbon nanotubes (CNTs)) [20] although organic nanomaterials are also manufactured (from polymers, monomers and lipids) [21]. Nano- and microplastics, on the other hand, consist specifically of synthetic polymers, produced by polymerisation of various monomers and covering a range of materials such as polyethylene (PE), polypropylene (PP), polystyrene (PS) and polyvinylchloride (PVC) [1,22]. Synthetic polymers differ in properties such as density, porosity and content of non-polymeric additives. Additives may constitute up to $50 \%$ of the total mass of plastics and can be composed of both organic and inorganic substances [23]. Hence, while nano- and microplastics consist of specific synthetic polymers (e.g. PE or PP), there are as many variations as there are combinations and ratios of additives. These additives may alter the properties of the material in such a way that it will behave differently in the environment and cause different environmental effects. The same is true for engineered nanomaterials: For engineered nanoparticles with a given chemical composition (e.g. $\mathrm{TiO}_{2}$ ), the properties change with different crystalline structures and surface coatings. At the same time, engineered nanomaterials can be made from a range of different materials and combinations of materials. An ongoing discussion within engineered nanomaterials relates to 'sameness': When can two particles be considered the same and when are they so different that they cannot? This has consequences for categorisation and 
read-across for regulatory purposes [24]. For example, if data exist on the toxicity of a certain nanomaterial, can these data then be used to assess the safety of a similar nanomaterial? On what parameters should these two particles be similar: size, shape, surface chemistry? And when is 'similar' similar enough to be considered 'the same'? This discussion will be relevant for nano- and microplastics, should legislative frameworks require regulatory data on their environmental safety. According to European legislation, polymers are currently exempted from registration under REACH [25]. However, this may change in the future, making the discussion of 'sameness' also relevant for primary nano- and microplastics. For secondary microplastics, sameness is likewise relevant to categorising particles occurring in the environment, as well as to comparing observed behaviour and effects of nano- and microplastic particles between different scientific studies.

The characteristics and chemical composition of particles have consequences for the feasibility of detection and quantification of particles, especially in environmental samples and biota. It is highly challenging to detect engineered nanomaterials in the environment, especially due to their small size. Under controlled laboratory conditions, with known nanomaterials, techniques based on electron microscopy, mass spectrometry and spectroscopy can be applied to investigating the behaviour of the nanomaterials in the test system [26]. However, applying the same techniques to the detection and quantification of nanomaterials in a natural environmental matrix is not straightforward - even when looking for a known nanomaterial. For this reason, monitoring data for engineered nanomaterials are practically non-existent. One of the main problems is that the nanomaterials may be modified through sample preparation (e.g., causing dissolution or aggregation), making it difficult to 'extract' the particles from the sample in their naturally occurring state [26]. Electron microscopy, in combination with elemental ratios, has successfully been applied in detecting $\mathrm{TiO}_{2}$ nanoparticles released from sunscreen into lake surface waters [27]. Comparing elemental ratios was necessary in order to distinguish natural Ti-bearing particles from their engineered counterparts. Even for engineered nanomaterials made of non-ubiquitous elements (e.g. Ag), detection is not straightforward due to complicated sample preparations, matrix interferences and analytical difficulties in distinguishing between different metal species [28].

Nano- and microplastics pose additional challenges due to their organic origin, affecting and limiting the analytical options when they are present in an organic matrix. While the larger-sized fractions can be collected or extracted fairly easily, for example, by filtering water samples or density-based fractionation of sand, it becomes increasingly difficult to distinguish smaller microplastics, and especially nanoplastics, from the surrounding environmental matrix. At the same time, secondary nano- and microplastics, which constitute the main environmental load of plastic particles, are irregular in shape, resulting from their formation through fragmentation rather than controlled production. Also, they are often transparent, semi-transparent or neutral in colour. A study has been carried out to compare stereomicroscopy and Fourier transform infrared spectroscopy (FT-IR) as 
identification methods for microplastics in environmental samples. White and transparent fragments were identified through FT-IR, but not easily detected by microscopy, leading to underestimation of the actual concentrations of microplastics [29]. In contrast, fibres, identified as cotton fibres by FT-IR, were mistaken for microplastics by stereomicroscopy, leading to overestimation of microplastic fibres using this technique [29].

The development of FT-IR combined with microspectroscopy (i.e. micro-FTIR) greatly improved the spatial resolution, allowing the identification of particles down to a few $\mu \mathrm{m}[30,31]$. The technique allows measurement of transmission and reflectance. The first gives a higher-quality spectrum, but is limited to thin samples, while the latter can also be applied to thick and opaque particles [32]. However, irregular surface structures (e.g. of plastic fragments) can lead to refractive errors when using the reflectance mode [30]. In this case, attenuated total reflectance (ATR) micro-FT-IR can be used to improve the quality of the spectrum. The standard FT-IR techniques rely on a visual pre-sorting of potential plastic particles, which is time-consuming and prone to errors [30]. Therefore, the coupling of micro-FT-IR with focal plane array detectors is considered a promising method for high throughput analysis of microplastics in complex environmental samples $[30,31,33]$. Currently, however, the technique is limited to particles larger than $10-20 \mu \mathrm{m}$, and sample preparation is labour-intensive. As for many of the analytical techniques used for engineered nanoparticles, FT-IR is particularly useful for controlled laboratory tests with microplastics of known composition. This material can be included in the spectral library and is then detected in samples. However, it can be difficult to use FT-IR to identify unknown plastics particles from environmental samples, as the spectra of polymers change due to the weathering and chemical changes of the surface of the plastics [29]. Raman spectroscopy is another commonly used method to identify plastic particles. In combination with microscopy (i.e. micro-Raman), a resolution of less than $1 \mu \mathrm{m}$ is achievable. However, the applicability of micro-Raman with automated spectral imaging for analysis of an entire sample is yet to be demonstrated for microplastics in environmental matrices [32].

The development of methods to detect and characterise nano- and microplastics in environmental matrices with a higher resolution, lower time consumption and high throughput is ongoing, comparable to the developments being made for engineered nanomaterials. The requirements for ideal analytical techniques are similar for both groups of particles. As previously described by Tiede et al. [26], such techniques should (a) cause minimal changes to the physical and chemical state of the particles during sample preparation; (b) provide information on several physicochemical parameters, such as chemical composition, size, shape, etc.; and (c) be able to handle complex, heterogeneous samples [26]. 


\section{Particles as a Vector for Co-pollutants}

One of the possible environmental processes, often discussed for both engineered nanomaterials and microplastics, is their ability to act as vectors for other pollutants. Through their use in, for example, consumer products and medical and industrial applications, engineered nanomaterials and primary microplastics will come into contact with other chemical substances, such as preservatives, surfactants and active ingredients in pharmaceutical drugs. Finally, through different disposal routes, the particles will come into contact with environmental contaminants present in, for example, waste water streams and landfill leachate. As a consequence, intentional and unintentional mixing of the particles with other chemical compounds takes place before, during and after their intended use. By this process, an otherwise inert and non-toxic particle potentially becomes a carrier of toxic compounds. At the same time hydrophobic pollutants with a low water solubility become more mobile when sorbed to plastic particles, which may increase their transport and consequently impact their distribution and bioavailability [34]. It has been shown that engineered nanomaterials can sorb and transport organic pollutants in the aquatic environment [35-37]. Similarly, nano- and microplastics have the potential to act as vectors for hydrophobic organic chemicals, as recently reviewed by Rochman [38].

With an increased surface area-to-volume ratio, smaller particles will generally have a larger capacity for adsorption of chemical substances (on an 'adsorption per particle mass' basis). At the same time, their small size may facilitate uptake by organisms and even potential translocation into different parts and organs. This vector function is governed by the properties of the pollutant and the particle [39]. Important particle properties include chemical composition, porosity, size and surface properties (coating, charge). Weathering processes can both increase and decrease sorption [40]. The formation of cracks and increased surface roughness leads to an increased surface area and, therefore, a potentially increased sorption capacity. Counteracting this, weathering may also change crystallinity, increase density and hardness and change surface charge. For instance, changes in surface charge as a result of weathering can increase the sorption of some substances and decrease the affinity for others [41].

Plastic to water partitioning coefficients $\left(\log K_{p w}\right)$ for various organic chemicals ( $\log K_{\text {ow }}$ from 0.90 to 8.76 ) have been collected for polydimethylsiloxane (PDMS), low density PE (LDPE), high density PE (HDPE), ultra-high molecular weight PE (UHMWPE), PP, PS and PVC [41]. Regression analysis showed generally good correlations between $\log K_{o w}$ and $\log K_{p w}$ and linear proportionality for LDPE and HDPE. This analysis suggests that the partitioning of chemicals into plastics is driven by hydrophobic interactions - similar to the partitioning of chemicals into animal lipids [41]. At the same time, pollutants may adhere to the particle surfaces. For example, it has been found that nanoplastics have a capability to adsorb hydrophobic pollutants, a process which can potentially be exploited in the removal of chemicals from contaminated soil and water [42]. Hence, for nano- and 
microplastics the processes of ad- and absorption may both be relevant to their potential role as pollutant vectors.

Many engineered nanomaterials are manufactured from inorganic materials - or inorganic carbon in the case of $\mathrm{C}_{60}$ fullerenes and CNTs. In these cases, the sorption of co-pollutants is governed by adsorption to the particle surface, rather than absorption into the particle matrix. Hence, the sorption capacity is determined by available adsorption sites on the surface of the nanomaterial. The differences in sorption processes between polymer particles and inorganic nanomaterials are illustrated in Fig. 2.

Nano- and microplastics as well as engineered nanomaterials have the potential to act as vectors for co-pollutants in the environment. The process will always depend on the specific chemical pollutant (e.g. $K_{o w}$ ), the specific particle properties (e.g. composition and size) and the properties of the surrounding media (e.g. pH), influencing the particle surface properties and the speciation and dissociation of the chemical pollutant. It has been proposed that the vector effect of particle-mediated transport of co-pollutants can be divided into three groups: (1) an environmental vector effect, whereby the co-pollutant is transported through the environment; (2) an organismal vector effect, whereby the co-pollutant is transported into organisms; and (3) a cellular vector effect whereby the co-pollutant is transported with the particle into cells [9]. Combining this with a proposed framework for different pollutant-particle interaction mechanisms, originally developed for engineered nanomaterials [37], the vector function of particle pollutants can be summarised as illustrated in Fig. 3.

Another type of vector function relates to leaching of substances that were originally part of the particle matrix. In the case of engineered nanomaterials, this is primarily metal ions (from metal and metal oxide nanomaterials) or release of coating materials. Similarly, polymer additives can leach from plastic particles. From the field of ecotoxicology of nanomaterials, the importance of properly quantifying ion release is becoming increasingly clear, as observed biological effects can often be directly linked to the concentration of free metal ions [8]. In the same way, the release of plastic additives should be examined when

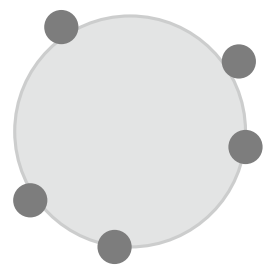

A

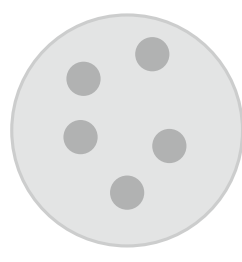

B

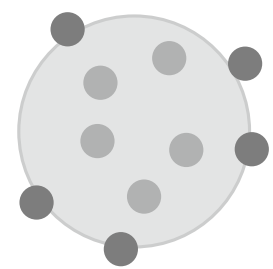

C

Fig. 2 Illustration of the difference between adsorption (a) (more pronounced for inorganic engineered nanomaterials) and absorption (b) (more pronounced for polymer particles). In the case of polymer particles, the sorption may also be a combination of ab- and adsorption processes (c) 


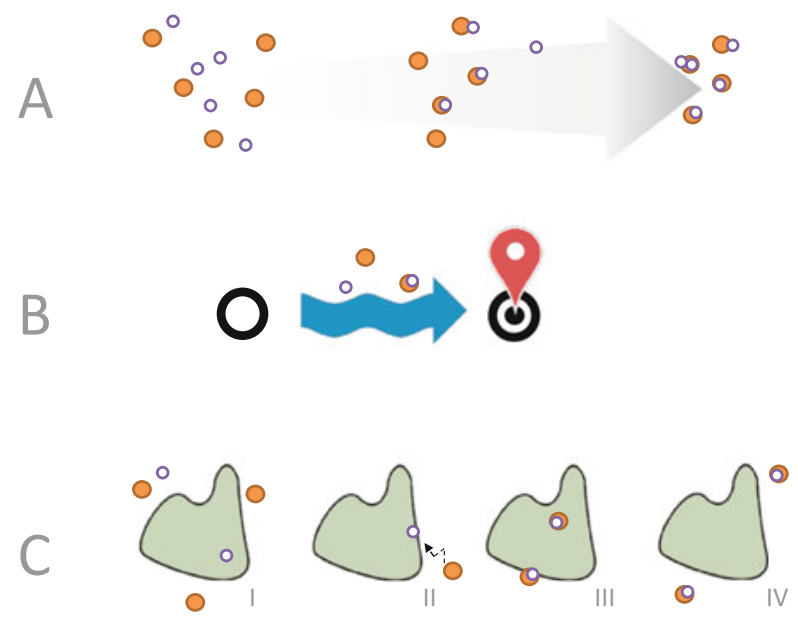

Fig. 3 Illustration of the potential vector function of particles. (a) The interaction between the particles (orange, filled) and the co-pollutants (purple, open) will depend on the properties of the particles, the pollutant and the surrounding medium. This will result in various degrees of absorption and/or adsorption. (b) The particles and pollutants are transported in the environment - individually and co-transported. This has been referred to as the 'environmental vector effect' [9]. (c) The particles and pollutants interact with biological organisms. This can be via 'independent action' whereby the particle and the pollutant interact with the organisms individually $(I)$. It can also be via desorption of the co-pollutant (or leaching of ions/additive), which subsequently interact with the organism (II). The pollutant can also be co-transported into the organisms and potentially further into cells $(I I I)$. This has been referred to as an organismal and cellular vector effect, respectively [9]. Finally, the particles can act as a 'trap' for the pollutants, thereby decreasing the interactions between the pollutant and the organisms (IV)

investigating the potential biological effects of nano- and microplastics. This will enable a differentiation between effects caused by the particle itself and effects caused by plastic additives.

\section{Biological Effects}

Engineered nanomaterials are often designed to have a certain reactivity, functionality or biological effect. As discussed, nano- and microplastics often stem from unintentional anthropogenic rather than engineered processes. Even when they are intentionally produced, they are not as such intended to be biologically active. Certain polymer additives may, however, have the purpose of, for example, preventing biotic or abiotic degradation. For both engineered nanomaterials and nano- and microplastics, it is therefore useful to consider their intended use and properties when evaluating their potential environmental risk. Engineered nanomaterials that are intended to have biocidal effects are likely to be more toxic to non-target organisms than materials intended to be inert. Similarly, plastic particles 
containing biocidal additives, plasticisers or flame retardants are likely to be more environmentally hazardous, as these substances may leach out of the polymer matrix.

One effect mechanism is being highlighted as important for both engineered nanomaterials and nano- and microplastics, namely, physical interactions between the particle and the organisms [43]. This includes inflammation and interference with the energy balance caused by uptake of particles into the gut, thereby limiting food uptake. Different types of engineered nanomaterials, as well as nanoplastics, have been observed to adhere to the surface of microalgae, potentially causing a physical shading effect on a cellular level [44]. Physical effects of microplastics on marine organisms have been reviewed recently [45], and mechanisms that have been described as potentially relevant include blockage of the digestive system, abrasion of tissues, blockage of feeding appendages of invertebrates, embedment in tissues, blockage of enzyme production, reduced feeding stimulus, nutrient dilution, decreased growth rates, lower steroid hormone levels and impaired reproduction. Table 1 presents an overview of effects in response to the physical particle properties that have been observed in different species.

The potential of microplastics to cause such physical effects on organisms depends on a number of factors. Particles with a high capacity to accumulate in

Table 1 Examples of biological effects observed in aquatic organisms after exposure to engineered nanoparticles or nano- and microplastics

\begin{tabular}{|c|c|}
\hline Engineered nanoparticles & Nano- and microplastics \\
\hline \multicolumn{2}{|l|}{ Molecular/cellular level } \\
\hline $\begin{array}{l}\text { Oxidative stress }^{\mathrm{a}} \\
\text { Inhibition of photosynthesis (shading) }\end{array}$ & $\begin{array}{l}\text { DNA damage and differential gene expression }{ }^{1} \\
\text { Cellular stress response and impaired } \\
\text { metabolism }^{\mathrm{m}}\end{array}$ \\
\hline \multicolumn{2}{|l|}{ Tissue level } \\
\hline $\begin{array}{l}\text { Histopathological changes } \\
\text { Transfer into cells }{ }^{\mathrm{d}}\end{array}$ & $\begin{array}{l}\text { Tissue damage } \\
\text { Transfer into tissues }^{\mathrm{o}}\end{array}$ \\
\hline \multicolumn{2}{|l|}{ Organ/organismal level } \\
\hline $\begin{array}{l}\text { Morphological malformation } \\
\text { Decreased swimming velocities }^{\mathrm{f}} \\
\text { Increased mucus production }^{\mathrm{g}} \\
\text { Toxic effects of released ions }^{\mathrm{h}} \\
\text { Decreased growth rates and biomass } \\
\text { production }^{\mathrm{i}} \\
\text { Moulting inhibition }^{\mathrm{j}} \\
\text { Impaired mobility }^{\mathrm{k}}\end{array}$ & $\begin{array}{l}\text { Impaired respiration }^{\mathrm{p}} \\
\text { Impaired feeding }^{\mathrm{q}} \\
\text { Impaired development and reproduction }^{\mathrm{r}} \\
\text { Decreased growth rates and biomass production } \\
\text { Behavioural changes }^{\mathrm{t}} \\
\text { Increased mortality }^{\mathrm{u}}\end{array}$ \\
\hline \multicolumn{2}{|c|}{ 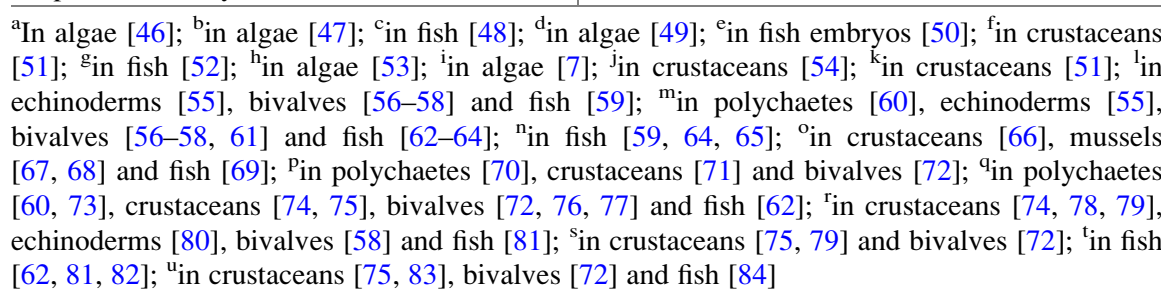 } \\
\hline
\end{tabular}


organisms and translocate into tissues are expected to have a stronger physical impact [45]. This is closely linked to particle size, as will be explained further below. Shape also plays an important role since irregular, sharp fragments are more likely to cause damage than round, smooth particles. Fibres are more likely to accumulate in the digestive system. The capacity of individual species to egest microplastics is also considered as an important factor because this process will determine how long an organism is exposed to the particles [45].

For nanomaterials, size-dependent changes in effects are of particular interest. The whole purpose of nanotechnology is to take advantage of the novel properties that come with a smaller size. For engineered nanomaterials, this involves, for example, the novel catalytic effects of some materials on the nanoscale including gold $(\mathrm{Au})$, titanium dioxide $\left(\mathrm{TiO}_{2}\right)$ and cerium dioxide $\left(\mathrm{CeO}_{2}\right)$. As larger-sized (bulk) materials, these are relatively inert, but with decreasing particle size and increasing surface area, they become reactive. Therefore, as particle size decreases, there is a tendency for toxicity to increase, even if the same material is relatively inert in its corresponding bulk (micron-sized) form [85]. In addition, the small size of engineered nanomaterials may enable their uptake into tissues and cells [49]. Observed biological effects of engineered nanomaterials in aquatic organisms include oxidative stress, inhibition of photosynthesis, tissue damage, impaired growth and development, behavioural changes and increased mortality (Table 1).

Similarly, the question for nano- and microplastics is therefore: Is it likely that a decrease in size will make them more hazardous? To answer this question, we will examine the two main causes for concern: novel properties and ingestion by organisms (and potential subsequent transfer into tissues). The novel properties that would occur for smaller-sized polymer particles are linked to their increased surface-to-volume ratio. With decreasing particle size, a larger fraction of the molecules will be present on the surface of the particle. As the surface is where interactions with the surrounding environment take place, this can lead to an increase in chemical reactions and biological interactions. For example, smaller particles may (on a mass basis) have a larger adsorption capacity compared to larger particles [86], which in turn is of relevance for the vector effects. The second concern relates to the potential to cross biological barriers. Nanosized particles, such as nanoplastics, are potentially more hazardous due to their easier uptake into tissues and cells [2]. Depending on particle size, different uptake routes into organisms are also involved. For example, the freshwater crustacean Daphnia magna normally catches prey (mainly algae) in the size range $0.4-40 \mu \mathrm{m}$ $[87,88]$. For particles or agglomerates that are within this size range, uptake can occur through active filtration, and at the same time unwanted particles can be rejected. Particles smaller than the preferred size are not actively taken up by the animals, but may instead enter the organisms through 'drinking' of the surrounding water, resulting in non-selective, uncontrolled uptake. Depending on the feeding strategies of specific aquatic organisms and their ability to actively select their food source, they may be able to regulate their uptake of microplastics, whereas nanoplastics may enter the organisms unintentionally. 


\subsection{Nano- and Microplastics in Standard Ecotoxicity Tests}

In the quest to determine the environmental risk posed by nano- and microplastics, laboratory-based experiments need to be carried out which analyse the effects of the particles under well-defined conditions. The number of controlled laboratory studies investigating the effects of nano- and microplastics on freshwater organisms is steadily increasing, and many different impacts have been observed - extending from the molecular and cellular to the physiological level (see Table 1). These include inflammation, disruption of lipid and amino acid metabolism, lower growth rates, decreased feeding rates, behavioural changes, impairment of reproduction and increased mortality [62, 64, 75, 79, 81, 82]. When studies involving marine organisms are also taken into account, the number and variety of biological effects of nano- and microplastics that have been found are even greater.

However, most effect studies differ greatly with respect to the parameters used, for example, particle type (different polymers, sizes, shapes, presence of chemicals), test species, exposure duration, exposure concentration and response variables. This makes it difficult to compare results between studies and hampers reproducibility. It can, therefore, be advantageous to apply standardised tests, which come with a number of benefits as they ensure controlled and reproducible test designs and inter-laboratory comparability. Another advantage of standardised ecotoxicity tests is the extensive knowledge base resulting from decades of testing the effects of chemicals on selected model organisms. For ecotoxicology of nanomaterials, this has been highlighted as a motivation for using standardised short-term tests as a starting point for gaining an insight into the fate and bioavailability of engineered nanomaterials in the environment [89]. By using a welldefined test system and a fully defined synthetic medium, other test parameters can be varied individually and in a controlled manner, thereby providing an insight into specific processes and mechanisms [90].

However, the use of standard test guidelines also comes with some potential disadvantages, especially for testing of particles. For freshwater systems, a commonly used species is the freshwater flea Daphnia magna, for which the OECD has developed two standard tests: an acute immobilisation test (48 h) (OECD TG 202) and a chronic reproduction test (21 days) (OECD TG 211). These tests were originally developed for soluble chemicals. Since particles show very different behaviours to soluble chemicals, it is challenging to apply the same test set-ups. Even so, some studies have used these standard tests to investigate the effects of nano- and microplastics. Casado et al. [91] conducted an acute immobilisation test with 55 and $110 \mathrm{~nm}$ polyethyleneimine PS beads and reported $\mathrm{EC}_{50}$ values of $0.8 \mathrm{mg} / \mathrm{l}$ and $0.7 \mathrm{mg} / \mathrm{l}$, respectively. The same test with $1 \mu \mathrm{m} \mathrm{PE}$ beads resulted in an $\mathrm{EC}_{50}$ value of $57.4 \mathrm{mg} / \mathrm{l}$ [83]. This huge difference could be a consequence of the different polymer types and sizes used in the studies, but it might also indicate that mortality is not a very sensitive biological response when it comes to plastic particles. Finally, it may be indicative of a problem that has been highlighted for tests with engineered nanomaterials: That reproducibility and data interpretation in 
standard ecotoxicity tests with particles, rather than soluble chemicals, are challenged by the dynamic nature of particles suspended in aqueous media [90]. Particle properties and behaviour may change as a function of time or as a result of interactions with test organisms and emitted biomolecules (e.g. exudates) [7]. It has therefore been recognised as essential in the work with engineered nanomaterials to conduct a particle and exposure characterisation before and during a laboratory test [26,92]. This includes an analysis of the size, shape, surface area and surface chemistry of the tested particle, as well as aggregation/agglomeration, sedimentation and dissolution behaviour in the test system, thereby providing information on exposure in both qualitative and quantitative terms. Furthermore, appropriate ways of dispersing the particles in aquatic media have been highlighted as an important area of future test method development [93]. The rationale behind thorough characterisation and carefully considered sample preparation methods relates to data interpretation and avoidance of the introduction of test artefacts. Such activities are currently rarely undertaken in the work with nano- and microplastics, but should be included in order to gain an insight into the behaviour of the particles in exposure media and the resulting influence on their interaction with test organisms.

Another aspect that needs to be taken into account is the leaching of molecules from particles. For engineered nanomaterials, work is ongoing within the OECD to develop test guidelines for investigating the dissolution of metal ions from metalcontaining nanomaterials [94]. In the case of plastic particles, the leaching of chemicals from the polymer matrix (e.g. additives or monomers) and the release of adhered co-pollutants can influence the test results. Appropriate test methods are therefore needed to investigate the actual release of plastic additives from nano- and microplastics under relevant conditions (media, temperature, $\mathrm{pH}$, etc.), and a control for the effects of chemicals and released additives or adhered pollutants needs to be included as a reference.

Transformation processes, such as oxidation/reduction, interaction with macromolecules, light exposure and biological transformation, can significantly influence the integrity, behaviour and persistence of nanomaterials in aquatic media [9597]. Depending on the specific conditions, dissolution and degradation can be enhanced or reduced. Enhanced dissolution may result in increased toxicity of, for example, metal and metal oxide nanomaterials. At the same time it may cause a gradual decrease in particle size [97]. For nano- and microplastics, aging/ weathering processes should also be accounted for as they may change particle properties (e.g. surface chemistry, polarity and density) and enhance fragmentation. It should be emphasised that a complete degradation of plastic particles under realistic environmental conditions has not yet been demonstrated [6, 98, 99]. While aging is potentially important for nanomaterials, and for nano- and microplastics, in the environment, the relevant aging processes and kinetics may differ. Based on current knowledge, nano- and microplastics may have a higher core persistence and lower release of soluble compounds than certain engineered nanomaterials (especially metal and metal oxide nanomaterials such as $\mathrm{ZnO}$ and $\mathrm{Ag}$ ). However, this is clearly an area of future research - for both nanomaterials and 
nano- and microplastics. Aging is currently not incorporated in standard ecotoxicity test protocols, but has been proposed for engineered nanomaterials [100]. There are also indications that aging of plastic particles can influence biological effects [79]. This aspect should therefore generally be considered in the future development of ecotoxicological tests for particle testing.

For test method developments, the field of ecotoxicity testing of nanomaterials has benefitted from the availability of reference materials (e.g. NIST Standard Reference Materials) and representative industrial nanomaterials (such as those from the JRC Nanomaterials Repository). Such materials are valuable for analytical method validation and for conducting comparable inter-laboratory and inter-species studies. The field of ecotoxicity testing of nano- and microplastics would similarly benefit from the establishment of sources of well-characterised, industrially and environmentally relevant materials of various sizes and compositions.

The applicability of current standard ecotoxicity tests has been questioned for engineered nanomaterials. Development of new test guidelines and guidance is under discussion, for example, within the OECD [101]. The same concerns apply to testing of nano- and microplastics: They represent a specific challenge due to their dynamic nature in environmental media, resulting in, for example, differences in relevant exposure routes (through food or other active uptake routes, grazing on sedimented materials, etc.), as well as potentially different effect mechanisms. Soluble molecules can be taken up into aquatic organism by diffusion and then distributed within the organism based on partitioning, e.g. to lipid tissues. Cellular uptake of soluble chemicals generally relates to passage of biological membranes, mainly through passive diffusion or active uptake, such as transport through ion channels or carrier-mediated transport [102]. In the tissues, they can act non-specifically, leading to narcosis, or specifically by inhibiting or affecting certain biological processes. In comparison, particle distribution is not governed by diffusion and partitioning. Uptake of particles by organisms depends on mechanisms such as feeding rather than molecular diffusion. On a cellular level, particles may be taken up through processes such as phagocytosis. Effects will therefore most likely differ from those of soluble chemicals. An essential aspect is therefore to determine sensitive biological endpoints for the exposure to particles, potentially moving away from the current standard test organisms. A limited number of response variables and test species can be seen as a disadvantage of standardised tests. Based on the argument above, it may further be claimed that 'no effect' in a standard test does not imply a lack of ecological impact of nano- and microplastics, as these tests may not cover the most sensitive endpoints and test species for particle exposure.

As mentioned, effects of microplastics have been observed on a molecular, cellular and physiological level (see Table 1). When performing ecotoxicity testing, the aim is to establish a dose-response relationship based on the underlying assumption that effects are strongly dependent on exposure dose/concentration and time. For engineered nanomaterials, however, an inverse relationship has been observed between concentration and agglomerate size, meaning that with higher particle concentrations, particles tend to form larger agglomerates 
[103]. High concentrations of engineered nanomaterials have also been linked to effects that are not due to an actual toxic response, but rather caused by an overloading of the test organisms with engineered nanomaterials, causing physical inhibition [8]. Testing of low, environmentally relevant particle concentrations during short exposure times may, however, not be sufficient to detect effects when using endpoints on a physiological level. Before an organism shows impairment to, for example, its reproduction or survival, multiple changes must take place on a cellular level. Cellular responses may therefore be more sensitive to microplastic particle stress compared with whole-organism responses. On this level, however, we are dealing with a complex network and huge number of reactions, which makes it challenging to find and define a meaningful, reliable set of response variables. If cellular responses are to be used as indicators of the potentially hazardous properties of nano- and microplastics, more research is needed to develop suitable (standard) test methods. Another option for testing the toxicity of relatively low concentrations of particles is chronic effect studies, as chronic endpoints can prove more sensitive than acute ecotoxicity. An added benefit of testing lower concentrations is that particle agglomeration/aggregation is reduced, leading to more stable exposure.

One major criticism of current nano- and microplastic ecotoxicity studies is their lack of realism and environmental relevance when selecting test parameters [104]. Pristine particles with a clearly defined, homogenous chemical composition are most often applied in laboratory tests. This is in sharp contrast to the particles present in the environment, which undergo transformation processes, potentially influencing their morphology, and, in the case of plastic, often contain various additives. This trade-off between environmental realism and standardised test conditions is not a dilemma that is unique to testing of particles [105]. It should be kept in mind that different testing paradigms inform different scientific and regulatory questions. In standard ecotoxicity, applying simplified test systems and often synthetic media, test parameters can more easily be controlled and modified one by one in order to gain deeper insight into the mechanisms of toxicity and particle uptake [89]. They are also developed to ensure data comparability and study repeatability. For example, data generated following OECD Test Guidelines and Good Laboratory Practice are considered to satisfy the criteria for Mutual Acceptance of Data and can be used for regulatory assessment purposes in all OECD member states, ideally minimising testing efforts and use of test animals [106]. More environmentally realistic studies can, on the other hand, provide caseand site-specific information on the effects of particle pollution under specific environmental conditions. They may also provide more realistic information with regard to the combined effects of multiple environmental stressors and their interactions with plastic particles. Standard ecotoxicity tests and more environmentally realistic studies should therefore be seen as complementary tools of equal importance but potentially addressing different questions of scientific and regulatory relevance. 


\subsection{Detecting and Quantifying Particle Uptake as a Prerequisite for Assessing the Effects of Nano- and Microplastics}

Research on the biological effects of nano- and microplastics is currently at the stage of determining possible responses and thereby investigating the interactions of organisms and plastic particles. For most organisms, there is a direct and obvious link between the uptake of nano- and microplastics by ingestion or ventilation and subsequent effects. Even so, knowledge on uptake itself is very limited, especially when it comes to quantification of this process, since the detection of small plastic particles is extremely challenging, as described earlier. Methods that have been used to quantify particle uptake include counting using a microscope and spectroscopy (Raman or FT-IR) of tissue samples. Furthermore, fluorescent particles are used for image analysis of gut sections, fluorescence microscopy and the measurement of fluorescence intensity of tissues as a proxy for the quantity of particles. All these methods have limitations and are either very difficult to use on a large scale (e.g. spectroscopy) or become increasingly challenged and even unusable with smaller particles and lower particle numbers. This is major drawback since most biological effects depend on the amount of plastic particles taken up into the organism. A possible way forward could be the use of plastic particles with a metal core which are easy to measure, even in small concentrations and sizes, by, for example, mass spectroscopy - using the same techniques as for nanoparticles. Such traceable nano- and microplastics do not reflect naturally occurring particles as found in the environment, but they could serve as model particles for investigating interactions of nano- and microplastics with biological systems. The technique could be used for precise quantification of particles as well as for localisation in tissues. Nanoparticles with a gold core and a polymer coating have previously been used in a number of studies, aimed at gaining an insight into the uptake of engineered nanomaterials in fish and daphnids [107].

\section{Lessons Learned... and the Way Ahead}

When the ecotoxicology of nanomaterials emerged as a scientific field around a decade ago, the already existing field of 'colloidal science' was somewhat overlooked. Over the years, it has become increasingly clear that many parallels can be drawn between the two fields. The links between particle behaviour, exposure and ecotoxicological effects, as highlighted here, demonstrate the highly interdisciplinary nature and complexity of this research field. Consequently, cooperation is required between scientists with backgrounds in biology, chemistry and colloidal science. Similarly, for studies of environmental behaviour and the effects of nanoand microplastics, it is clearly important to draw on experience from ecotoxicology of nanomaterials as well as colloidal science. This is the key to moving forwards 
towards an understanding of their potential environmental effects. This applies to general scientific knowledge as well as ongoing work on developing appropriate test methods that are applicable to the testing of particle pollutants rather than soluble chemicals.

Based on experience within the field of engineered nanomaterials, we recommend that the following aspects be considered in work with nano- and microplastics:

- Development of clear, common definitions for plastic particle categorisation

- Thorough particle characterisation in exposure studies (including particle intrinsic properties, aggregation, agglomeration, sedimentation, dissolution, etc.)

- Inclusion of chemical leaching controls (monomers, additives, etc.)

- Development and use of reference materials for method validation and comparison

- Development of protocols for ecotoxicity testing, sample preparation and analytical methods to minimise test artefacts

- Studies into the influence of environmental transformation processes ('aging') on nano- and microplastic behaviour and ecotoxicity

- Development of analytical techniques that introduce minimal changes to the plastic particles during sample preparation, provide information on several physicochemical parameters and can handle complex, heterogeneous samples.

While we should draw on the existing knowledge on engineered nanomaterials, it is equally important to understand where the similarities begin and where they end. In some respects, nano- and microplastics are likely to present different environmental, analytical and methodological problems compared to engineered nanomaterials, and this should be considered in the planning of experiments and in making informed decisions regarding endpoints and tests of interest.

Finally, it is very important to understand the fundamental effect mechanisms associated with nano- and microplastics: Which properties make them hazardous? This is the way forwards towards replacing problematic plastic materials with safer alternatives in consumer products and industrial applications. Such considerations are important when discussing strategies for future plastic manufacturing, minimising environmental risks and increasing the potential for plastic reuse and recycling.

\section{References}

1. Andrady AL (2011) Microplastics in the marine environment. Mar Pollut Bull 62:1596-1605. doi:10.1016/j.marpolbul.2011.05.030

2. Koelmans AA, Besseling E, Shim WJ (2015) Nanoplastics in the aquatic environment. Critical review. In: Bergmann M, Gutow L, Klages M (eds) Marine anthropogenic litter. Springer, Cham, pp 325-340. doi:10.1007/978-3-319-16510-3_12

3. Arthur C, Baker J, Bamford H (2009) Proceedings of the international research workshop on the occurrence, effects, and fate of microplastic marine debris. Group, 530 
4. Browne MA, Galloway T, Thompson R (2007) Microplastic - an emerging contaminant of potential concern? Integr Environ Assess Manag 3:297-297. doi:10.1002/ieam.5630030215

5. European Commission (EC) (2011) Commission recommendation of 18 October 2011 on the definition of nanomaterial (2011/696/EU). Off J Eur Union 54, L275:38-40

6. Lambert S, Wagner M (2016) Formation of microscopic particles during the degradation of different polymers. Chemosphere 161:510-517. doi:10.1016/j.chemosphere.2016.07.042

7. Hartmann NB, Engelbrekt C, Zhang J, Ulstrup J, Kusk KO, Baun A (2013) The challenges of testing metal and metal oxide nanoparticles in algal bioassays: titanium dioxide and gold nanoparticles as case studies. Nanotoxicology 7:1082-1094. doi:10.3109/17435390.2012. 710657

8. Skjolding LM, Sørensen SN, Hartmann NB, Hjorth R, Hansen SF, Baun A (2016) A critical review of aquatic ecotoxicity testing of nanoparticles - the quest for disclosing nanoparticle effects. Angew Chemie 55:15224-15239. doi:10.1002/ange.201604964

9. Syberg K, Khan FR, Selck H, Palmqvist A, Banta GT, Daley J, Sano L, Duhaime MB (2015) Microplastics: addressing ecological risk through lessons learned. Environ Toxicol Chem 34:945-953. doi:10.1002/etc.2914

10. Gouin T, Avalos J, Brunning I, Brzuska K, de Graaf J, Kaumanns J, Koning T, Meyberg M, Rettinger K, Schlatter H, Thomas J, Van Welie R, Wolf T (2015) Use of micro-plastic beads in cosmetic products in Europe and their estimated emissions to the North Sea environment. SOFW 3:40-46

11. Lassen C, Hansen SF, Magnusson K, Norén F, Hartmann NB, Jensen PR, Nielsen TG, Brinch A (2015) Microplastics: occurrence, effects and sources of releases to the environment in Denmark, Danish Environmental Protection Agency, Copenhagen K, (2015) environmental project no. 1793

12. Kramm J, Völker C (2017) Understanding the risks of microplastics. A social-ecological risk perspective. In: Wagner M, Lambert S (eds) Freshwater microplastics: emerging environmental contaminants? Springer, Heidelberg. doi:10.1007/978-3-319-61615-5_11 (in this volume)

13. Duis K, Coors A (2016) Microplastics in the aquatic and terrestrial environment: sources (with a specific focus on personal care products), fate and effects. Environ Sci Eur 28:2. doi:10.1186/s12302-015-0069-y

14. Napper IE, Thompson RC (2016) Release of synthetic microplastic plastic fibres from domestic washing machines: effects of fabric type and washing conditions. Mar Pollut Bull 112:39-45. doi:10.1016/j.marpolbul.2016.09.025

15. US Congress (2016) Public Law 114-114, 114th Congress an act, H.R.1321 - Microbeadfree waters act 2015. Public Law 3129-3130

16. UK Department for Environment, Food \& Rural Affairs (2016) Microbead ban announced to protect sealife. https://www.gov.uk/government/news/microbead-ban-announced-to-protectsealife. Accessed 1 Dec 2016

17. Convery F, McDonnell S, Ferreira S (2007) The most popular tax in Europe? Lessons from the Irish plastic bags levy. Environ Resour Econ 38:1-11. doi:10.1007/s10640-006-9059-2

18. Schneider J, Karigl B, Reisinger H, Oliva J, Süßenbacher E, Read B (2011) A European refunding scheme for drinks containers, European Parliament, Directorate General for External Policies of the Union, Brussels, Belgium

19. Lambert S, Wagner M (2017) Microplastics are contaminants of emerging concern in freshwater environments: an overview. In: Wagner M, Lambert S (eds) Freshwater microplastics: emerging environmental contaminants? Springer, Heidelberg. doi:10.1007/978-3319-61615-5_1 (in this volume)

20. Hendren CO, Mesnard X, Dröge J, Wiesner MR (2011) Estimating production data for five engineered nanomaterials as a basis for exposure assessment. Environ Sci Technol 45: 2562-2569. doi:10.1021/es103300g

21. Lacour S (2013) Emerging questions for emerging technologies: is there a law for the nano? In: Brayner R et al (eds) Nanomaterials: a danger or a promise? A chemical and biological perspective. Springer, London, pp 357-378. doi:10.1007/978-1-4471-4213-3 
22. Thompson RC, Swan SH, Moore CJ, vom Saal FS (2009) Our plastic age. Philos Trans R Soc B Biol Sci 364:1973-1976. doi:10.1098/rstb.2009.0054

23. Oehlmann J, Schulte-Oehlmann U, Kloas W, Jagnytsch O, Lutz I, Kusk KO, Wollenberger L, Santos EM, Paull GC, Van Look KJW, Tyler CR (2009) A critical analysis of the biological impacts of plasticizers on wildlife. Philos Trans R Soc B Biol Sci 364:2047-2062. doi:10. 1098/rstb.2008.0242

24. The Organisation for Economic Co-operation and Development (OECD) (2016) Joint Meeting of the Chemicals Committee and the Working Party on Chemicals, Pesticides and Biotechnology Categorisation of Manufactured Nanomaterials Workshop Report. Series on the Safety of Manufactured Nanomaterials, ENV/JM/MONO(2016)9

25. European Chemicals Agency (ECHA) (2012) Guidance for monomers and polymers, version 2.0. European Chemicals Agency, Helsinki, Finland

26. Tiede K, Boxall A, Tear S, Lewis J, David H, Hassellov M (2008) Detection and characterization of engineered nanoparticles in food and the environment. Food Addit Contam Part A 25:795-821. doi:10.1080/02652030802007553

27. Gondikas AP, von der Kammer F, Reed RB, Wagner S, Ranville JF, Hofmann T (2014) Release of $\mathrm{TiO}_{2}$ nanoparticles from sunscreens into surface waters: a one-year survey at the old Danube Recreational Lake. Environ Sci Technol 48:5415-5422. doi:10.1021/es405596y

28. Guo H, Xing B, Hamlet LC, Chica A, He L (2016) Surface-enhanced Raman scattering detection of silver nanoparticles in environmental and biological samples. Sci Total Environ 554-555:246-252. doi:10.1016/j.scitotenv.2016.02.084

29. Song YK, Hong SH, Jang M, Han GM, Rani M, Lee J, Shim WJ (2015) A comparison of microscopic and spectroscopic identification methods for analysis of microplastics in environmental samples. Mar Pollut Bull 93:202-209. doi:10.1016/j.marpolbul.2015.01.015

30. Harrison JP, Ojeda JJ, Romero-González ME (2012) The applicability of reflectance microFourier-transform infrared spectroscopy for the detection of synthetic microplastics in marine sediments. Sci Total Environ 416:455-463. doi:10.1016/j.scitotenv.2011.11.078

31. Löder MGJ, Kuczera M, Mintenig S, Lorenz C, Gerdts G (2015) Focal plane array detectorbased micro-Fourier-transform infrared imaging for the analysis of microplastics in environmental samples. Environ Chem 12:563. doi:10.1071/EN14205

32. Löder MGJ, Gerdts G (2015) Methodology used for the detection and identification of microplastics - a critical appraisal. In: Bergmann M, Gutow L, Klages M (eds) Marine anthropogenic litter. Springer, Cham, pp 201-227. doi:10.1007/978-3-319-16510-3_8

33. Tagg AS, Sapp M, Harrison JP, Ojeda JJ (2015) Identification and quantification of microplastics in wastewater using focal plane array-based reflectance micro-FT-IR imaging. Anal Chem 87:6032-6040. doi:10.1021/acs.analchem.5b00495

34. Teuten EL, Rowland SJ, Galloway TS, Thompson RC (2007) Potential for plastics to transport hydrophobic contaminants. Environ Sci Technol 41:7759-7764. doi:10.1021/ es071737s

35. Hofmann T, von der Kammer F (2009) Estimating the relevance of engineered carbonaceous nanoparticle facilitated transport of hydrophobic organic contaminants in porous media. Environ Pollut 157:1117-1126. doi:10.1016/j.envpol.2008.10.022

36. Canesi L, Ciacci C, Balbi T (2015) Interactive effects of nanoparticles with other contaminants in aquatic organisms: friend or foe? Mar Environ Res 111:128-134. doi:10.1016/j. marenvres.2015.03.010

37. Hartmann NB, Baun A (2010) The nano cocktail: ecotoxicological effects of engineered nanoparticles in chemical mixtures. Integr Environ Assess Manag 6:311-313. doi:10.1002/ ieam.39

38. Rochman CM (2015) The complex mixture, fate and toxicity of chemicals associated with plastic debris in the marine environment. In: Bergmann M, Gutow L, Klages M (eds) Marine anthropogenic litter. Springer, Cham, pp 117-140. doi:10.1007/978-3-319-16510-3_5 
39. Ziccardi LM, Edgington A, Hentz K, Kulacki KJ, Kane Driscoll S (2016) Microplastics as vectors for bioaccumulation of hydrophobic organic chemicals in the marine environment: a state-of-the-science review. Environ Toxicol Chem 35:1667-1676. doi:10.1002/etc.3461

40. Teuten EL, Saquing JM, Knappe DRU, Barlaz MA, Jonsson S, Bjorn A, Rowland SJ, Thompson RC, Galloway TS, Yamashita R, Ochi D, Watanuki Y, Moore C, Viet PH, Tana TS, Prudente M, Boonyatumanond R, Zakaria MP, Akkhavong K, Ogata Y, Hirai H, Iwasa S, Mizukawa K, Hagino Y, Imamura A, Saha M, Takada H (2009) Transport and release of chemicals from plastics to the environment and to wildlife. Philos Trans R Soc B Biol Sci 364:2027-2045. doi:10.1098/rstb.2008.0284

41. O'Connor IA, Golsteijn L, Hendriks AJ (2016) Review of the partitioning of chemicals into different plastics: consequences for the risk assessment of marine plastic debris. Mar Pollut Bull. doi:10.1016/j.marpolbul.2016.07.021

42. Brandl F, Bertrand N, Lima EM, Langer R (2015) Nanoparticles with photoinduced precipitation for the extraction of pollutants from water and soil. Nat Commun 6:7765. doi:10. $1038 /$ ncomms 8765

43. Scherer C, Weber A, Lambert S, Wagner M (2017) Interactions of microplastics with freshwater biota. In: Wagner M, Lambert S (eds) Freshwater microplastics: emerging environmental contaminants? Springer, Heidelberg. doi:10.1007/978-3-319-61615-5_8 (in this volume)

44. Hartmann NB, Legros S, Von der Kammer F, Hofmann T, Baun A (2012) The potential of $\mathrm{TiO}_{2}$ nanoparticles as carriers for cadmium uptake in Lumbriculus variegatus and Daphnia magna. Aquat Toxicol 118-119:1-8. doi:10.1016/j.aquatox.2012.03.008

45. Wright SL, Thompson RC, Galloway TS (2013) The physical impacts of microplastics on marine organisms: a review. Environ Pollut 178:483-492. doi:10.1016/j.envpol.2013.02.031

46. von Moos N, Slaveykova VI (2013) Oxidative stress induced by inorganic nanoparticles in bacteria and aquatic microalgae - state of the art and knowledge gaps. Nanotoxicology 8: 605-630. doi:10.3109/17435390.2013.809810

47. Sørensen SN, Engelbrekt C, Lützhøft H-CH, Jiménez-Lamana J, Noori JS, Alatraktchi FA, Delgado CG, Slaveykova VI, Baun A (2016) A multimethod approach for investigating algal toxicity of platinum nanoparticles. Environ Sci Technol. doi:10.1021/acs.est.6b01072

48. Johari SA, Kalbassi MR, Yu IJ, Lee JH (2015) Chronic effect of waterborne silver nanoparticles on rainbow trout (Oncorhynchus mykiss): histopathology and bioaccumulation. Comp Clin Pathol 24:995-1007. doi:10.1007/s00580-014-2019-2

49. von Moos N, Bowen P, Slaveykova VI (2014) Bioavailability of inorganic nanoparticles to planktonic bacteria and aquatic microalgae in freshwater. Environ Sci Nano 1:214-232. doi:10.1039/c3en00054k

50. Asharani PV, Lian Wu Y, Gong Z, Valiyaveettil S (2008) Toxicity of silver nanoparticles in zebrafish models. Nanotechnology 19:255102. doi:10.1088/0957-4484/19/25/255102

51. Artells E, Issartel J, Auffan M, Borschneck D, Thill A, Tella M, Brousset L, Rose J, Bottero JY, Thiéry A (2013) Exposure to cerium dioxide nanoparticles differently affect swimming performance and survival in two Daphnia species. PLoS One 8:1-11. doi:10.1371/journal. pone. 0071260

52. Smith CJ, Shaw BJ, Handy RD (2007) Toxicity of single walled carbon nanotubes to rainbow trout, (Oncorhynchus mykiss): respiratory toxicity, organ pathologies, and other physiological effects. Aquat Toxicol 82:94-109. doi:10.1016/j.aquatox.2007.02.003

53. Heinlaan M, Ivask A, Blinova I, Dubourguier HC, Kahru A (2008) Toxicity of nanosized and bulk $\mathrm{ZnO}, \mathrm{CuO}$ and $\mathrm{TiO}_{2}$ to bacteria Vibrio fischeri and crustaceans Daphnia magna and Thamnocephalus platyurus. Chemosphere 71:1308-1316. doi:10.1016/j.chemosphere.2007. 11.047

54. Dabrunz A, Duester L, Prasse C, Seitz F, Rosenfeldt R, Schilde C, Schaumann GE, Schulz R (2011) Biological surface coating and molting inhibition as mechanisms of $\mathrm{TiO}_{2}$ nanoparticle toxicity in Daphnia magna. PLoS One 6:1-7. doi:10.1371/journal.pone.0020112 
55. Della Torre C, Bergami E, Salvati A, Faleri C, Cirino P, Dawson KA, Corsi I (2014) Accumulation and embryotoxicity of polystyrene nanoparticles at early stage of development of sea urchin embryos Paracentrotus lividus. Environ Sci Technol 48:12302-12311. doi:10. $1021 / \mathrm{es} 502569 \mathrm{w}$

56. Avio CG, Gorbi S, Milan M, Benedetti M, Fattorini D, D’Errico G, Pauletto M, Bargelloni L, Regoli F (2015) Pollutants bioavailability and toxicological risk from microplastics to marine mussels. Environ Pollut 198:211-222. doi:10.1016/j.envpol.2014.12.021

57. Paul-Pont I, Lacroix C, González Fernández C, Hégaret H, Lambert C, Le Goïc N, Frère L, Cassone A-L, Sussarellu R, Fabioux C, Guyomarch J, Albentosa M, Huvet A, Soudant P (2016) Exposure of marine mussels Mytilus spp. to polystyrene microplastics: toxicity and influence on fluoranthene bioaccumulation. Environ Pollut 216:724-737. doi:10.1016/j. envpol.2016.06.039

58. Sussarellu R, Suquet M, Thomas Y, Lambert C, Fabioux C, Pernet MEJ, Le Goïc N, Quillien V, Mingant C, Epelboin Y, Corporeau C, Guyomarch J, Robbens J, Paul-Pont I, Soudant P, Huvet A (2016) Oyster reproduction is affected by exposure to polystyrene microplastics. Proc Natl Acad Sci 113:2430-2435. doi:10.1073/pnas.1519019113

59. Karami A, Romano N, Galloway T, Hamzah H (2016) Virgin microplastics cause toxicity and modulate the impacts of phenanthrene on biomarker responses in African catfish (Clarias gariepinus). Environ Res 151:58-70. doi:10.1016/j.envres.2016.07.024

60. Wright SL, Rowe D, Thompson RC, Galloway TS (2013) Microplastic ingestion decreases energy reserves in marine worms. Curr Biol 23:R1031-R1033. doi:10.1016/j.cub.2013.10. 068

61. Canesi L, Ciacci C, Bergami E, Monopoli MP, Dawson KA, Papa S, Canonico B, Corsi I (2015) Evidence for immunomodulation and apoptotic processes induced by cationic polystyrene nanoparticles in the hemocytes of the marine bivalve Mytilus. Mar Environ Res 111: 1-7. doi:10.1016/j.marenvres.2015.06.008

62. Cedervall T, Hansson L-A, Lard M, Frohm B, Linse S (2012) Food chain transport of nanoparticles affects behaviour and fat metabolism in fish. PLoS One 7:e32254. doi:10.1371/ journal.pone. 0032254

63. Greven A-C, Merk T, Karagöz F, Mohr K, Klapper M, Jovanović B, Palić D (2016) Polycarbonate and polystyrene nanoplastic particles act as stressors to the innate immune system of fathead minnow (Pimephales promelas). Environ Toxicol Chem 35:3093-3100. doi:10.1002/etc.3501

64. Lu Y, Zhang Y, Deng Y, Jiang W, Zhao Y, Geng J, Ding L, Ren H (2016) Uptake and Accumulation of polystyrene microplastics in zebrafish (Danio rerio) and toxic effects in liver. Environ Sci Technol 50:4054-4060. doi:10.1021/acs.est.6b00183

65. Pedà C, Caccamo L, Fossi MC, Gai F, Andaloro F, Genovese L, Perdichizzi A, Romeo T, Maricchiolo G (2016) Intestinal alterations in European sea bass Dicentrarchus labrax (Linnaeus, 1758) exposed to microplastics: preliminary results. Environ Pollut 212: 251-256. doi:10.1016/j.envpol.2016.01.083

66. Rosenkranz P, Chaudhry Q, Stone V, Fernandes TF (2009) A comparison of nanoparticle and fine particle uptake by Daphnia magna. Environ Toxicol Chem 28:2142-2149

67. Browne MA, Dissanayake A, Galloway TS, Lowe DM, Thompson RC (2008) Ingested microscopic plastic translocates to the circulatory system of the mussel, Mytilus edulis (L.) Environ Sci Technol 42:5026-5031. doi:10.1021/es800249a

68. von Moos N, Burkhardt-Holm P, Köhler A (2012) Uptake and effects of microplastics on cells and tissue of the blue mussel Mytilus edulis L. after an experimental exposure. Environ Sci Technol 46:11327-11335. doi:10.1021/es302332w

69. Kashiwada S (2006) Distribution of nanoparticles in the see-through medaka (Oryzias latipes). Environ Health Perspect 114:1697-1702. doi:10.1289/ehp.9209 
70. Green DS, Boots B, Sigwart J, Jiang S, Rocha C (2016) Effects of conventional and biodegradable microplastics on a marine ecosystem engineer (Arenicola marina) and sediment nutrient cycling. Environ Pollut 208:426-434. doi:10.1016/j.envpol.2015.10.010

71. Watts AJR, Urbina MA, Goodhead R, Moger J, Lewis C, Galloway TS (2016) Effect of microplastic on the gills of the shore crab Carcinus maenas. Environ Sci Technol 50: 5364-5369. doi:10.1021/acs.est.6b01187

72. Rist SE, Assidqi K, Zamani NP, Appel D, Perschke M, Huhn M, Lenz M (2016) Suspended micro-sized PVC particles impair the performance and decrease survival in the Asian green mussel Perna viridis. Mar Pollut Bull 111:213-220. doi:10.1016/j.marpolbul.2016.07.006

73. Besseling E, Wegner A, Foekema EM, van den Heuvel-Greve MJ, Koelmans A a (2013) Effects of microplastic on fitness and PCB bioaccumulation by the lugworm Arenicola marina (L.) Environ Sci Technol 47:593-600. doi:10.1021/es302763x

74. Cole M, Lindeque P, Fileman E, Halsband C, Galloway TS (2015) The impact of polystyrene microplastics on feeding, function and fecundity in the marine copepod Calanus helgolandicus. Environ Sci Technol 49:1130-1137. doi:10.1021/es504525u

75. Ogonowski M, Schür C, Jarsén Å, Gorokhova E (2016) The effects of natural and anthropogenic microparticles on individual fitness in Daphnia magna. PLoS One 11:e0155063. doi:10.1371/journal.pone.0155063

76. Wegner A, Besseling E, Foekema EM, Kamermans P, Koelmans AA (2012) Effects of nanopolystyrene on the feeding behavior of the blue mussel (Mytilus edulis L.) Environ Toxicol Chem 31:2490-2497. doi:10.1002/etc.1984

77. Cole M, Galloway TS (2015) Ingestion of nanoplastics and microplastics by Pacific oyster larvae. Environ Sci Technol 49:14625-14632. doi:10.1021/acs.est.5b04099

78. Lee K-W, Shim WJ, Kwon OY, Kang J-H (2013) Size-dependent effects of micro polystyrene particles in the marine copepod Tigriopus japonicus. Environ Sci Technol 47: 11278-11283. doi:10.1021/es401932b

79. Besseling E, Wang B, Lürling M, Koelmans AA (2014) Nanoplastic affects growth of S. obliquus and reproduction of D. magna. Environ Sci Technol 48:12336-12343. doi:10. 1021/es503001d

80. Nobre CR, Santana MFM, Maluf A, Cortez FS, Cesar A, Pereira CDS, Turra A (2015) Assessment of microplastic toxicity to embryonic development of the sea urchin Lytechinus variegatus (Echinodermata: Echinoidea). Mar Pollut Bull 92:99-104. doi:10.1016/j. marpolbul.2014.12.050

81. Lönnstedt OM, Eklov P (2016) Environmentally relevant concentrations of microplastic particles influence larval fish ecology. Science 352:1213-1216. doi:10.1126/science.aad8828

82. de Sá LC, Luís LG, Guilhermino L (2015) Effects of microplastics on juveniles of the common goby (Pomatoschistus microps): confusion with prey, reduction of the predatory performance and efficiency, and possible influence of developmental conditions. Environ Pollut 196:359-362. doi:10.1016/j.envpol.2014.10.026

83. Rehse S, Kloas W, Zarfl C (2016) Short-term exposure with high concentrations of pristine microplastic particles leads to immobilisation of Daphnia magna. Chemosphere 153:91-99. doi:10.1016/j.chemosphere.2016.02.133

84. Mazurais D, Ernande B, Quazuguel P, Severe A, Huelvan C, Madec L, Mouchel O, Soudant P, Robbens J, Huvet A, Zambonino-Infante J (2015) Evaluation of the impact of polyethylene microbeads ingestion in European sea bass (Dicentrarchus labrax) larvae. Mar Environ res 112:78-85. doi:10.1016/j.marenvres.2015.09.009

85. Nel A, Xia T, Mädler L, Li N (2006) Toxic potential of materials at the nanolevel. Science 311:622-627. doi:10.1126/science.1114397

86. Wiesner MR, Lowry GV, Casman E, Bertsch PM, Matson CW, Di Giulio RT, Liu J, Hochella MF (2011) Meditations on the ubiquity and mutability of nano-sized materials in the environment. ACS Nano 5:8466-8470. doi:10.1021/nn204118p

87. Gophen M, Geller W (1984) Filter mesh size and food particle uptake by Daphnia. Oecologia 64:408-412. doi:10.1007/BF00379140 
88. Geller W, Müller H (1981) The filtration apparatus of Cladocera: filter mesh-sizes and their implications on food selectivity. Oecologia 49:316-321. doi:10.1007/BF00347591

89. Baun A, Hartmann NB, Grieger K, Kusk KO (2008) Ecotoxicity of engineered nanoparticles to aquatic invertebrates: a brief review and recommendations for future toxicity testing. Ecotoxicology 17:387-395. doi:10.1007/s10646-008-0208-y

90. Hartmann NB (2011) Ecotoxicity of engineered nanoparticles to freshwater organisms. $\mathrm{PhD}$ thesis, Technical University of Denmark, Kgs. Lyngby

91. Casado MP, Macken A, Byrne HJ (2013) Ecotoxicological assessment of silica and polystyrene nanoparticles assessed by a multitrophic test battery. Environ Int 51:97-105. doi:10. 1016/j.envint.2012.11.001

92. Petersen EJ, Henry TB, Zhao J, MacCuspie RI, Kirschling TL, Dobrovolskaia MA, Hackley V, Xing B, White JC (2014) Identification and avoidance of potential artifacts and misinterpretations in nanomaterial ecotoxicity measurements. Environ Sci Technol 48: 4226-4246. doi:10.1021/es4052999

93. Hartmann NB, Jensen KA, Baun A, Rasmussen K, Rauscher H, Tantra R, Cupi D, Gilliland D, Pianella F, Riego Sintes JM (2015) Techniques and protocols for dispersing nanoparticle powders in aqueous media-is there a rationale for harmonization? $\mathrm{J}$ Toxicol Environ Heal Part B 18:299-326. doi:10.1080/10937404.2015.1074969

94. Rasmussen K, González M, Kearns P, Sintes JR, Rossi F, Sayre P (2016) Review of achievements of the OECD working party on manufactured nanomaterials' testing and assessment programme. From exploratory testing to test guidelines. Regul Toxicol Pharmacol 74:147-160. doi:10.1016/j.yrtph.2015.11.004

95. Lin D, Tian X, Wu F, Xing B (2010) Fate and transport of engineered nanomaterials in the environment. J Environ Qual 39:1896. doi:10.2134/jeq2009.0423

96. Turco R, Bischoff M, Tong Z, Nies L (2011) Environmental implications of nanomaterials: are we studying the right thing? Curr Opin Biotechnol 22:527-532. doi:10.1016/j.copbio. 2011.05.006

97. Lowry GV, Gregory KB, Apte SC, Lead JR (2012) Transformations of nanomaterials in the environment. Environ Sci Technol 46:6893-6899. doi:10.1021/es300839e

98. Brandon J, Goldstein M, Ohman MD (2016) Long-term aging and degradation of microplastic particles: comparing in situ oceanic and experimental weathering patterns. Mar Pollut Bull 110:299-308. doi:10.1016/j.marpolbul.2016.06.048

99. ter Halle A, Ladirat L, Gendre X, Goudouneche D, Pusineri C, Routaboul C, Tenailleau C, Duployer B, Perez E (2016) Understanding the fragmentation pattern of marine plastic debris. Environ Sci Technol 50:5668-5675. doi:10.1021/acs.est.6b00594

100. Sørensen SN, Baun A (2015) Controlling silver nanoparticle exposure in algal toxicity testinga matter of timing. Nanotoxicology 9:201-209. doi:10.3109/17435390.2014.913728

101. Kühnel D, Nickel C (2014) The OECD expert meeting on ecotoxicology and environmental fate - towards the development of improved OECD guidelines for the testing of nanomaterials. Sci Total Environ 472:347-353. doi:10.1016/j.scitotenv.2013.11.055

102. Sijm DTHM, Rikken MGJ, Rorije E, Traas TP, Mclachlan MS, Peijnenburg WJGM (2007) Transport, accumulation and transformation processes. In: van Leeuwen CJ, Vermeire TG (eds) Risk assessment of chemicals: an introduction. Springer, Dordrecht, pp 73-158. doi:10. 1007/978-1-4020-6102-8_3

103. Baalousha M, Sikder M, Prasad A, Lead J, Merrifield R, Chandler GT (2016) The concentration-dependent behaviour of nanoparticles. Environ Chem 13(1). doi:10.1071/ EN15142

104. Phuong NN, Zalouk-Vergnoux A, Poirier L, Kamari A, Châtel A, Mouneyrac C, Lagarde F (2016) Is there any consistency between the microplastics found in the field and those used in laboratory experiments? Environ Pollut 211:111-123. doi:10.1016/j.envpol.2015.12.035

105. Wickson F, Hartmann NB, Hjorth R, Hansen SF, Wynne B, Baun A (2014) Balancing scientific tensions. Nat Nanotechnol 9:870-870. doi:10.1038/nnano.2014.237 
106. The Organisation for Economic Co-operation and Development (OECD) (1981) Decision of the Council concerning the mutual acceptance of data in the assessment of chemicals. 12 May 1981-C(81)30/FINAL. Amended on 26 November 1997-C(97)186/FINAL., Paris, France

107. Skjolding LM 2015 Bioaccumulation and trophic transfer of engineered nanoparticles in aquatic organisms. PhD thesis, Technical University of Denmark, Kgs. Lyngby

Open Access This chapter is licensed under the terms of the Creative Commons Attribution 4.0 International License (http://creativecommons.org/licenses/by/4.0/), which permits use, sharing, adaptation, distribution and reproduction in any medium or format, as long as you give appropriate credit to the original author(s) and the source, provide a link to the Creative Commons license and indicate if changes were made.

The images or other third party material in this chapter are included in the chapter's Creative Commons license, unless indicated otherwise in a credit line to the material. If material is not included in the chapter's Creative Commons license and your intended use is not permitted by statutory regulation or exceeds the permitted use, you will need to obtain permission directly from the copyright holder. 